\title{
Exploring the Determinants of Intention to Quit and Awareness Regarding III Effects and Control Policies of Tobacco among Health Workers of a Tertiary Care Hospital in North India
}

\author{
Nidhi Prasad ${ }^{1}$, Dharamvir Ranjan Bharati ${ }^{2}$, Sanjay Kumar Choudhary ${ }^{3}$, Binay Kumar ${ }^{4}$ \\ ${ }^{1}$ ESIC Faridabad, Haryana \\ NH-3, NIT, Faridabad 121001 India \\ 1,2,3 Indira Gandhi Institute of Medical Sciences, Patna \\ Allahabad Bank, Bailey Rd, Sheikhpura, Patna, Bihar 800014, India \\ ${ }^{4} \mathrm{NSMCH}$, Bihta, Patna \\ Amhara, Bihta, Bihar 801103, India
}

\begin{abstract}
Introduction: Sociodemographic factor, awareness of the health effects and legislative law can lead to an increase in cessation of tobacco. Tobacco related knowledge and awareness are found to be better in people working in the health care sector as compared to the general population. The objective of the study was to find the prevalence of quitting rate amongst the health workers and perceived harmful effects on health, tobacco types and awareness of the anti -smoking legislation law in India among the health care workers working in a tertiary care hospital. Methods: A cross-sectional study was conducted among 306 hospital staff (196 housekeeping staff and 110 nursing orderlies) at a tertiary care hospital of Faridabad in 2018. Convenience sampling was conducted, and data were collected through pre tested semi structured questionnaires on sociodemographic details, awareness of ill effects of tobacco and intention to quit. Results: Among 133 current tobacco users, intention to quit smoking was present in only 96 respondents $(72.18 \%)$. There was association between age, marital status and type of family with the intention to quit. 63 respondents $(21 \%)$ were unaware that smoking causes lung cancer and 115 (38\%) of the total respondents did not consider smokeless tobacco as a causal risk factor for cancer. A total of 180 respondents (58.8\%) were not aware of anti-tobacco control laws in India. Moreover, it was found that health concern was commonest reason of intention to quit. Conclusions: Intention to quit tobacco among study participants was low, so there is need to look for knowledge gaps about harms of different types of products and antitobacco legislation. More comprehensive tobacco cessation services should also be prioritized in the heath sector.
\end{abstract}

Keywords: awareness of ill effects, COTPA, India, intention to quit, tobacco

Corresponding Author:

Nidhi Prasad

Email:drnidhi2001@gmail.com

Phone:9560740734

\section{INTRODUCTION}

Tobacco consumption in any form, is one of the leading avoidable causes of deaths all over the world, accounting to more than 8 million deaths a year worldwide (WHO Report on the Global Tobacco Epidemic, 2019). These deaths also include those exposed to second-hand smoke, and an increase in the death rate is also predicted in years to come. The majority of smokeless tobacco (SLT) users $(80 \%)$ are from the South East Asia region, which is alarming.

There is a need to prioritize tobacco due to high morbidity and mortality associated with its use. South-East Asian countries has supported World Health Organisation Framework Convention on
Tobacco Control (WHO FCTC) recommendations, including Indonesia but execution of law is not very strict. By October 2013, Indian provinces except Lakshadweep and Meghalaya banned gutka (a mixture of tobacco, crushed areca nut, spices and other ingredients, placed between gum and cheek) sale but the enforcement is not uniform across India. A Study conducted in seven states (Assam, Bihar, Gujarat, Karnataka, Madhya Pradesh, Maharashtra and Orissa) and the National Capital Region was conducted to assess the impact of Gutka ban in India, which revealed that most of the users purchased tobacco and mixed it with a packet of pan masala (World Health Organization, 2014). This innovating idea adversely has an impact on the declining rate of smoking habit. Thus, there should be better reinforcement of the regulation of tobacco, as done by Cigarettes and other Tobacco Products Acts (COTPA) in India (Mishra et al., 2016). To reduce the consumption, there are several 
existing strategies, namely laws on marketing and sale, price regulation by government authorities, prohibition of public place smoking, sale to minor, promotional advertisements. (The Cigarettes and Other Tobacco Products Act ,2003). However, these laws and policies do not cover SLT effectively. So, there is shift in preference to other forms of tobacco to escape stringent laws for smoking.

Current practices of tobacco use along with intention to quit can help us plan strategies for cessation programmes. There is an established role of health care professionals in tobacco control (World Health Organization., 2005). With self motivation, they can execute the tobacco control programmes at ground level. Health care staff who consume tobacco may not be effective counsellors and may not provide effective cessation support to for smoking cessation in the same way as their nontobacco counterparts. Attempts to quit are higher if counselling is done by health care providers (Kar et al., 2020). Tobacco cessation counselling should be seen as an essential responsibility of healthcare professionals (Maharani et al., 2021).

It is time to start a no tobacco culture among health professionals to make hospital premises free from all forms of tobacco. Studies have shown $21.1 \%$ of the overall prevalence of smoking in health care providers (Omotowo, Ndibuagu and Ezeoke, 2016). In addition, tobacco industries tend to utilize the loophole in policies and regulation to reach every each nook and corner of the country. Thus, this study aims to find the prevalence of intention to quit and its reasons, as well as to assess participants' current knowledge about different tobacco forms, associated ill effects and anti-tobacco laws among health workers. Gaps should be identified in the knowledge and legislation implementation so that the intention to quite smoking can be enforced and enacted effectively as well as extended immediately on both ST and SLT.

\section{METHODS}

This research was a cross sectional study. Interview was conducted using a semi structured questionnaire that was pretested. The study was done at a tertiary care hospital, Faridabad from June to December 2018. All the housekeeping and nursing orderlies working in a tertiary care centre, Faridabad who gave their consent were included. All administrative, managerial, and supervisory staff and participants who did not give consent to participate were excluded.
All the housekeeping and nursing orderlies working in the tertiary care centre were evaluated in the study to find out how many of them had the intention to quit smoking. There were 306 workers in total according to the list obtained from the supervisors, 196 of whom were housekeeping staff and 110 of whom were nursing orderlies. All employed workers were included, and consent was obtained from all of the participants and after that they were included in the study.

Semi structured questionnaire which had been pretested was used. Data were collected through personal interviews one to one using a semi-structured questionnaire. Part I consisted of questions on socio demographic details and part II had details of tobacco use, pattern of use, past usage, products used, intention to quit, frequency, factors determining tobacco use, reasons for use, intention to quit in the past and reasons for wanting to quit, perception of health effects by tobacco form, both smoking and smokeless, belief regarding the different form used and also knowledge of legislation for tobacco products. Codes were assigned to study population for anonymity. Permission from supervisors from both groups of the study population was obtained, and workers were told above the purpose of the study before being interviewed. Data were collected during breaks.

The quantitative data were entered in Microsoft Excel sheet and analysed using Epi info version 7. Descriptive statistics including frequencies and proportions were calculated for categorical variables. The Chi square test was applied to find out association between socio demographic factors and intention to quit smoking with a significance level of $p<0.05$. The Ethical clearance was obtained from the institute's ethical committee for biomedical research (letter no. 134/A/11/16/Academic/ $\mathrm{MC} / 2016 / 106)$. Informed consent was taken from all participants before gathering any information. Operational definitions used include: Current users: Regular tobacco users within 1 month from the date of interview; Nontobacco users: Never or occasionally used tobacco; Ex -tobacco users: Stopped more than 1 month prior to the interview.

\section{RESULTS}

In this current study, around $72 \%(96 / 133)$ of the tobacco users showed intention to quit tobacco. The intention to quit was higher among the age group of 18-29 years old (48\%), followed by the age group of $30-39$ years old $(34 \%)(p=0.01)$. The 
Table 1. Socio demography profile of tobacco users with intention to quit $(\mathrm{N}=133)$

\begin{tabular}{|c|c|c|c|c|c|}
\hline \multirow[b]{2}{*}{ Variable } & \multicolumn{2}{|c|}{ Intention to quit } & \multirow{2}{*}{$\begin{array}{c}\text { Total } \\
\text { Users N (\%) } \\
\text { 133(100) }\end{array}$} & \multirow[b]{2}{*}{$\begin{array}{c}\text { Chi } \\
\text { square, (d.f) }\end{array}$} & \multirow[b]{2}{*}{ P value } \\
\hline & $\begin{array}{l}\text { Yes n (\%) } \\
96(72.18)\end{array}$ & $\begin{array}{c}\text { No } \\
\\
37(27.82\end{array}$ & & & \\
\hline \multicolumn{6}{|c|}{ Age Groups (years old) } \\
\hline $18-29$ & $46(48)$ & $28(76)$ & $74(56)$ & \multirow{3}{*}{$8.6(2)$} & \multirow{3}{*}{0.001} \\
\hline $30-39$ & $33(34)$ & $5(13)$ & $38(28)$ & & \\
\hline$>40$ & $17(18)$ & $4(11)$ & $21(16)$ & & \\
\hline \multicolumn{6}{|l|}{ Gender } \\
\hline Male & $90(94)$ & $37(100)$ & $127(95)$ & \multirow{2}{*}{ - } & \multirow{2}{*}{ - } \\
\hline Female & $6(6)$ & 0() & $6(5)$ & & \\
\hline \multicolumn{6}{|l|}{ Marital Status } \\
\hline Married & $71(74)$ & $35(95)$ & $106(80)$ & \multirow{2}{*}{5.811} & \multirow{2}{*}{0.015} \\
\hline Unmarried/Widow & $25(26)$ & $2(5)$ & $27(20)$ & & \\
\hline \multicolumn{6}{|l|}{ Education } \\
\hline$<5$ & $28(31)$ & $9(29)$ & $37(38)$ & \multirow{3}{*}{$1.30(2)$} & \multirow{3}{*}{0.521} \\
\hline $5-10$ & $24(26)$ & 7(19) & $31(27)$ & & \\
\hline$>10$ & $44(43)$ & $21(63)$ & $65(35)$ & & \\
\hline \multicolumn{6}{|l|}{ Occupation } \\
\hline Housekeeping & $72(75)$ & $22(59.5)$ & $94(70.7)$ & \multirow{2}{*}{$3.1(1)$} & \multirow{2}{*}{0.0778} \\
\hline Nursing orderly & $24(25)$ & $15(40.5)$ & $39(29.3)$ & & \\
\hline \multicolumn{6}{|l|}{ Type of tobacco } \\
\hline Smokeless tobacco & $45(47)$ & $16(43.2)$ & $61(45.9)$ & \multirow{3}{*}{$0.15(2)$} & \multirow{3}{*}{0.927} \\
\hline Smoked tobacco & $37(38)$ & $15(40.5)$ & $52(39.1)$ & & \\
\hline Both & $14(15)$ & $6(16.3)$ & $20(15)$ & & \\
\hline \multicolumn{6}{|l|}{ Type of family } \\
\hline Joint & $71(74)$ & $22(60)$ & $93(70)$ & \multirow{2}{*}{$18.5(1)$} & \multirow{2}{*}{0.00017} \\
\hline Nuclear & $25(26)$ & $15(40)$ & $40(30)$ & & \\
\hline \multicolumn{6}{|l|}{ Frequency } \\
\hline Daily & $46(48)$ & $24(65)$ & $70(52.6)$ & \multirow{2}{*}{$3.1(1)$} & \multirow{2}{*}{0.794} \\
\hline Occasional & $50(52)$ & $13(35)$ & $63(47.4)$ & & \\
\hline
\end{tabular}

participants who were married $(\mathrm{p}=0.015)$ and lived in joint family $(0.0001)$ had higher intention to quit. Almost two third of the participants with intention to quit were married. Those who were living in a joint family $71(74 \%)$ had greater intention to quit in comparison to those who were in nuclear family $15(26 \%)$. Types of tobacco consumed and the frequency of tobacco use were not significantly associated with quitting intentions. $(\mathrm{P}=0.927)$. Among all the health care workers in this study, $45.6 \%(133 / 306)$ reported tobacco use. Smokeless form of tobacco was used by 45 respondents (47\%), whereas 37 respondents (38\%) used smoked form and 14 respondents $(15 \%)$ were dual users (Table $1)$.

The most alarming finding in this current study was the fact that about 180 people $(58.8 \%)$ working in a tertiary health care were not aware of any aspect of tobacco control laws. Moreover, statistically awareness about the types of product, was significantly different among users and nonusers. Overall, housekeeping and nursing orderlies perceived the harm similarly, with few exceptions. Only $18.3 \%$ of the total participants had knowledge of de-addiction centres on campus, while $81.6 \%$ were not aware of any de-addiction centres. Those with knowledge did not report to the de-addiction centre to seek any help (Table 2). It was also reported that the majority of tobacco users believed smoking causes cancer (201 respondents or 66\%) respiratory system-related disorders such as bronchitis (142 respondents or $46.4 \%$ ), tuberculosis (159 respondents or $51.9 \%)$, non-communicable diseases $(97$ respondents or $31.6 \%)$ and kidney problems $(6$ respondents or 4.5\%). Among 173 non- Users 102 respondents $(59 \%)$ were aware that using tobacco 
(smoking) could cause tuberculosis, followed by cancer (93 respondents or $54 \%$ ), bronchitis 78 respondents or $45 \%$ ), non-communicable Diseases 59 respondents or 34\%) and kidney problems (12 respondents or 7\%). Out of the total 306 respondents, 63 respondents (20.5\%) had no knowledge about the harmful effects of tobacco use. Among current users, it was reported that tobacco (smokeless) could cause cancer (184 respondents or $60.1 \%$ ), followed by teeth discolouration 67 respondents or $21.8 \%$ ), while 115 respondents $(37.5 \%)$ did not know about the ill effects of tobacco use on physical or mental health.

Meanwhile, among non-users 121 respondents $(70 \%)$ knew that tobacco in any form could cause cancer, followed by $40(23 \%)$ respondents who were aware of discolouration of teeth on chronic use. About 115 out of 306 respondents did not know any adverse effect of tobacco use on health. The majority of smokers believed that smoking could cause respiratory cancer, accounting for $81 \%$, and non-communicable diseases, kidney problems and TB of $29 \%, 48 \%$ and $43 \%$ respectively (Table 3 ).

Concern for health and illness were the major reasons of both smokeless tobacco users $(30.7 \%)$ and smokers $29.4 \%$, while other reasons such as financial concern and relief of symptoms accounted for $11.5 \%$ and $9.6 \%$ respectively among smokeless tobacco users. Moreover, concern for the family and children was reported to reach $14.7 \%$ and $11.7 \%$ respectively, among smokers. Mostly hookah users reported that they discontinued it due to time consuming and complicated preparation (Table 4).

\section{DISCUSSION}

There is an increasing trend and changing preference of tobacco consumption among health workers. Thus, this study is imperative to assess intention to quit, knowledge regarding tobacco products used, existing laws, and their implementation.

Out of the total study population, tobacco use was prevalent among less than half of the respondents in which two thirds were in the housekeeping and one third were in the nursing section. A similar trend is seen in health care workers in upper middle-income countries and low middle income countries where the prevalence rates were

Table 2. Knowledge of the study participants regarding the types of tobacco products, anti-tobacco legislative measures and de-addiction centres related to the prevention of tobacco use, among current users and non-users of tobacco as well as heath care workers $(\mathrm{N}=306)$

\begin{tabular}{|c|c|c|c|c|c|}
\hline $\begin{array}{c}\text { Knowledge of the } \\
\text { Participants }\end{array}$ & Category & $\begin{array}{c}\text { Current users } \\
(\mathrm{N}=133) \mathrm{n}(\%)\end{array}$ & $\begin{array}{c}\text { Non users }(\mathrm{N}=173) \\
\mathrm{n}(\%)\end{array}$ & $\begin{array}{c}\text { Total }(\mathrm{N}=306) \\
n(\%)\end{array}$ & P value \\
\hline \multirow{4}{*}{$\begin{array}{l}\text { Tobacco form that } \\
\text { is harmful }\end{array}$} & Smoking form & $18(13)$ & $42(24)$ & $60(19.6)$ & \multirow{4}{*}{$\begin{array}{l}\mathrm{P}<0.00001 \\
\mathrm{X} 230.8\end{array}$} \\
\hline & Smokeless form & $50(38)$ & $63(36)$ & $113(36.9)$ & \\
\hline & Both forms & $21(16)$ & $51(30)$ & $72(23.5)$ & \\
\hline & No knowledge & $44(33)$ & $17(10)$ & 61(19.9) & \\
\hline \multirow{2}{*}{ Anti- Tobacco Law } & Yes & $69(52)$ & $57(33)$ & $126(41.1)$ & \multirow{2}{*}{$\begin{array}{l}\mathrm{P}<0.0008 \\
\mathrm{X} 211.13\end{array}$} \\
\hline & No & $64(48)$ & $116(67)$ & $180(58.8)$ & \\
\hline \multirow{2}{*}{$\begin{array}{l}\text { De-Addiction } \\
\text { Centre }\end{array}$} & Yes & $25(19)$ & $31(18)$ & $56(18.3)$ & \multirow{2}{*}{$\begin{array}{c}\text { P } 0.84 \\
\mathrm{X} 2.0388\end{array}$} \\
\hline & No & $108(81)$ & $142(82)$ & $250(81.6)$ & \\
\hline
\end{tabular}

Table 3. Distribution of awareness of harmful effects of tobacco among health care staff $(\mathrm{N}=306)$

\begin{tabular}{llccc}
\hline \multirow{2}{*}{ Awareness of ill Effects } & \multicolumn{1}{c}{ Characteristics } & $\begin{array}{c}\text { Current users (N=133) } \\
\mathbf{n}(\mathbf{\%})\end{array}$ & $\begin{array}{c}\text { Non users (N=173) } \\
\mathbf{n}(\mathbf{\%})\end{array}$ & $\begin{array}{c}\text { Total (N=306) } \\
\mathbf{n}(\mathbf{\%})\end{array}$ \\
& Non communicable diseases & $38(29)$ & $59(34)$ & $97(31.6)$ \\
& Bronchitis & $64(48)$ & $78(45)$ & $142(46.4)$ \\
\multirow{3}{*}{ Smoking } & Tuberculosis & $57(43)$ & $102(59)$ & $159(51.9)$ \\
& Kidney Problem & $6(4.5)$ & $12(7)$ & $18(5.8)$ \\
& Cancer & $108(81)$ & $93(54)$ & $201(66)$ \\
& Not aware & $15(11)$ & $48(28)$ & $63(20.5)$ \\
\hline \multirow{3}{*}{ Smokeless } & Teeth discolouration & $27(20)$ & $40(23)$ & $67(21.8)$ \\
& Cancer & $63(47)$ & $121(70)$ & $184(60.1)$ \\
& Not Aware & $54(41)$ & $61(35)$ & $115(37.5)$ \\
\hline
\end{tabular}


Table 4. Reasons for wanting to quit smoking $(\mathrm{N}=96)$

\begin{tabular}{|c|c|c|c|}
\hline $\begin{array}{l}\text { Reasons for } \\
\text { wanting to quit } \\
\text { smoking }\end{array}$ & $\begin{array}{c}\text { Smokeless } \\
\text { t o b a c c o } \\
\text { users n }(\%)\end{array}$ & $\begin{array}{c}\text { Smokers, } n \\
(\%)\end{array}$ & $\begin{array}{c}\text { Dual form, } \\
\text { n (\%) }\end{array}$ \\
\hline $\begin{array}{l}\text { Concern for } \\
\text { health and } \\
\text { illness }\end{array}$ & $16(30.7 \%)$ & $10(29.4)$ & $3(30)$ \\
\hline $\begin{array}{l}\text { Advice from } \\
\text { Doctor }\end{array}$ & $3(5.7)$ & $3(8.8)$ & $1(10)$ \\
\hline $\begin{array}{l}\text { Warning by } \\
\text { TV ads }\end{array}$ & $1(1.9)$ & $2(5.8)$ & - \\
\hline $\begin{array}{l}\text { Concern for } \\
\text { children }\end{array}$ & $4(7.6)$ & $4(11.7)$ & - \\
\hline $\begin{array}{l}\text { Concern for the } \\
\text { family }\end{array}$ & $5(9.6)$ & $5(14.7)$ & $4(40)$ \\
\hline $\begin{array}{l}\text { Financial } \\
\text { concern }\end{array}$ & $6(11.5)$ & $2(5.8)$ & - \\
\hline $\begin{array}{l}\text { Bad smell } \\
\text { and teeth } \\
\text { discolouration }\end{array}$ & $2(3.8)$ & 0 & - \\
\hline $\begin{array}{l}\text { Concern for } \\
\text { profession }\end{array}$ & $4(7.6)$ & $1((2.9)$ & - \\
\hline $\begin{array}{l}\text { Joined puja/ } \\
\text { Satsang }\end{array}$ & $3(5.7)$ & $1(2.9)$ & - \\
\hline $\begin{array}{l}\text { Relief of } \\
\text { symptoms }\end{array}$ & $5(9.6)$ & 0 & - \\
\hline $\begin{array}{l}\text { Time } \\
\text { consuming and } \\
\text { cumbersome }\end{array}$ & $2(3.8)$ & $4(11.7)$ & $1(10)$ \\
\hline $\begin{array}{l}\text { Diagnosed with } \\
\text { any disease }\end{array}$ & $1(1.9)$ & $2(5.8)$ & $1(10)$ \\
\hline Total & $52(100)$ & $34(100)$ & $10(100)$ \\
\hline
\end{tabular}

almost similar or higher than the general population (Nilan et al., 2019).

Tobacco consumption was the highest among low socioeconomic status (SES), with inclination towards smokeless tobacco (SLT) (Shekhawat et al., 2017). Around two thirds of the tobacco users had intention to quit tobacco. Among those who wanted to quit almost half used the smokeless form followed by the smoked form and dual forms respectively, which was higher than the regulation of the Ministry of Health and Family Welfare Government of India (2017) but lower than GATS2's survey in 2016-2017 in Haryana . Intention to quit was also higher in younger age groups (Kar et al., 2020). With the introduction of a tobacco-free hospital policy at hospitals, an observation was conducted on healthcare staff taking some alternatives. A few revealed to continue smoking during their breaks, by exiting the hospital premises, and smoking in the bathroom (mainly for the smokeless tobacco). In this study, association between tobacco control policies and quit rates was also noted (Feliu et al., 2019). Often housekeeping staff used tobacco as means of relaxation during gathering after their duty hours. "Chewing and Working" was common in the housekeeping staff as they used SLT forms, so they could manage to escape from getting noticed by their supervisors (Prasad et al., 2020). The products were also easy to find in shops in vicinity as these shops were not in the subject of complaint of the existing tobacco law. Staff, therefore, could easily leave breaks, smoke, and come back or purchase the cigarette from the shops if they did not carry them from home in the morning. On the other hand, nursing orderlies used smoked tobacco, but due to a shorter break period and its foul smell after use they avoided it during duty hours. This staff had noticed no signages for smokeless tobacco but were instructed by their supervisor that its use was prohibited in hospital premises. Most of them supported this policy, but due to a lack of continuous monitoring it was difficult to implement.

Intention to quit smoking both among housekeeping staff and nursing orderlies, was mainly due to health and family concerns. Knowledge of negative consequences specifically for smokeless tobacco on health has also led to cessation attempt (Hussen and Etu, 2019). It is also seen that the desire to quit smoking was due to the associated harms, the provision of a good example to society, and medical specialty.

Põld and Pärna (2018) also stated that knowledge regarding de-addiction centres in the campus was also very poor among participants, and those who had knowledge rarely sought help for de-addiction. Tobacco users had lesser knowledge than non tobacco users, and they would underate its adverse effects. Awareness of ill effects of tobacco use among participants was less than what was reported in GATS 2. There are studies that reported inadequate knowledge of the harm from SLT use and legislation against a ban on smoking in public places (Murthy et al., 2018; Vankhuma et al., 2020). Peoples' knowledge and belief also vary among different groups regarding the two forms (smoked and smokeless tobacco). The consumed form was rated safe compared to other forms. Moreover, a few also did not recognize gutka as a tobacco product. Gutka and pan masala products under the same brand names, allow manufacturers to circumvent laws. Thus, there should be a ban on these advertisements as they are able to advertise a product that appears identical to tobacco-containing gutka (World Health Organization Report.2014). Undoubtedly there is 
progress with respect to tobacco control policies, but it is still not implemented effectively and evenly to tackle smokeless tobacco issues throughout India. There should be visibility of the anti-tobacco campaigns at work site and health professionals must be actively involved in promoting tobacco cessation and be trained according to focussed strategies as there is low demand for assistance to quit (Mohan, Lando and Panneer, 2018; Murthy et al., 2018). It is also found that communication on the health effects of smokeless tobacco use within the populations addresses the false beliefs and has a positive impact (Rahman et al., 2015) Increase in the size of pictorial warning can make the message more visible, and it is also a cost-effective way of communication which can lead to behavioural changes as there are previous studies stating that pictorial warning depicted did not refrain people from using tobacco (Yaddanapalli et al., 2019; Mullapudi et al., 2019).

Currently, health warnings on cigarette packages in India are in full compliance with MPOWER recommendations. However, there should be a complete ban on point of sale (POS) advertisement which is lacking in the current setting as POS advertising has become strategic locations for tobacco companies to advertise their brands.

Due to inherent challenges of tobacco such as the diversity of product types, consumption patterns, packaging, nicotine levels and harmful potential, involvement of formal and informal sectors, litigation by marketing companies and understated problems, a multipronged investigative and remedial approach with the implementation of WHO-FCTC provisions is required (Sinha et al., 2018; Murthy et al., 2018; 2018 GLOBAL PROGRESS REPORT on Implementation of the WHO Framework Convention on Tobacco Control). Counselling services, quitlines, medical assistance, and pharmacotherapy are important for eliminating tobacco dependence. In low resource settings like India, with limited access to pharmacotherapy, there is a need to evaluate costeffective behavioural interventions, particularly on smokeless forms of tobacco use.

\section{CONCLUSION}

Health staff play a crucial role in tobacco control program. Working in a hospital environment does not ensure healthy lifestyle. Counselling along with pharmacological support should be extended to health workers during working hours in the hospital itself. Provisions for monitoring and strict compliance with anti-tobacco law should be in place.
Taxes on SLT are very small, much lower than taxes on cigarettes. In addition, the small packs and sachets make SLT affordable. Loose tobacco packs near hospitals, offices and educational institutions should also be banned as this will immediately refrain people from buying as it will be costlier to buy a whole pack. It is expected that this could lead to the emergence of vendor licencing which can cover mostly all states in the future. In addition, Newer methods like geo mapping to monitor the areas around hospital can be utilized. Certain signs or informal messages used by vendors for the sale of tobacco should be identified and dealt. Evidencebased support, if feasible, should be provided, but if it not possible very brief advice can be provided. Healthcare staff cannot be left unsupported as many of them might be willing to give up their habit if they get any help. This can be a great opportunity for tobacco control measures and effective implementation.

\section{ACKNOWLEDGEMENTS}

The author would like to thank the management and supervisors for their cordial help. The author would also like to thank the Medical social workers of the department for their extended support for the completion of this research.

\section{REFERENCES}

Feliu, A. et al. (2019) 'Impact of Tobacco Control Policies on Smoking Prevalence and Quit Ratios in 27 European Union Countries from 2006 to 2014', Tobacco Control, 28(1), pp. 101-109.

Hussen, M. A. and Etu, E. S. (2019) 'The state of Smokeless Tobacco Cessation in a Context Lacking Cessation Services: Evidence from Ethiopia', Tobacco Induced Diseases, 17(October), pp. $1-8$

Kar, S. et al. (2020) 'Willingness to Quit Tobacco and its Correlates among Indian Tobacco users- Findings from the Global Adult Tobacco Survey India, 2016-17', Journal of Postgraduate Medicine, 66(3), pp. 141-148.

Maharani, D. A. et al. (2021) 'Intention to Provide Tobacco Cessation Counseling among Indonesian Dental Students and Association with the Theory of Planned Behavior', BMC Oral Health, 21(1).

Ministry of Health and Family Welfare Government of India (2017) 'Global adult tobacco survey, India 2016-17’, February-2014, p. 360. 
Mishra, S. et al. (2016) 'Trends in Bidi and Cigarette Smoking in India from 1998 to 2015, by Age, Gender and Education', BMJ Global Health, 1(1), pp. 1-8.

Mohan, P., Lando, H. A. and Panneer, S. (2018) 'Assessment of Tobacco Consumption and Control in India', Integrative Medicine Insights, 9,pp. 1-8.

Mullapudi, S. et al. (2019) 'A pilot study to assess compliance and impact of health warnings on tobacco products in the Udupi district of Karnataka State, India', Tobacco Induced Diseases, 17(May),pp. 1-5.

Murthy, P. et al. (2018) 'Smokeless tobacco (SLT) use and cessation in India: Lessons from user and health care provider perspectives', Asian Journal of Psychiatry, 32, pp. 137-142.

Nilan, K. et al. (2019) 'Prevalence of tobacco use in healthcare workers: A systematic review and meta-analysis', PLoS ONE, 14(7), pp. 1-26.

Omotowo, I. B., Ndibuagu, E. O. and Ezeoke, U. (2016) 'Cigarette Smoking and Attitudes Concerning Its Control among Healthcare Workers in Enugu, South-East, Nigeria', Health, 08(11), pp. 1049-1058.

Põld, M. and Pärna, K. (2018) 'Factors Associated with Desire to Quit Smoking among Estonian Physicians: Cross-sectional Data of 2002 and 2014', Tobacco Prevention \& Cessation, 4(July), pp. 1-9.

Prasad, N. et al. (2020) 'Tobacco use among Health Care Workers of Tertiary Care Center of Faridabad, Haryana, India', Clinical Epidemiology and Global Health, 8(2), pp. 394-398.
Rahman, M. A. et al. (2015) 'Why do Bangladeshi People use Smokeless Tobacco Products?', Asia-Pacific Journal of Public Health, 27(2), pp. NP2197-NP2209.

Shekhawat, K. S. et al. (2017) 'Smokeless Tobacco: Profiling Sachets and Pattern of use among Low Socioeconomic Population of Puducherry', Contemporary Clinical Dentistry, 8(2), pp. 225-230.

Sinha, D. N. et al. (2018) 'The Poorest of Poor Suffer the Greatest Burden from Smokeless Tobacco use: A study from 140 countries', Nicotine and Tobacco Research, 20(12), pp. 1529-1532.

Vankhuma, C. et al. (2020) 'Tobacco use patterns and tobacco-related awareness in medical students of Delhi', Clinical Epidemiology and Global Health, 8(1), pp. 83-86.

World Health Organization. (2005) The role of health professionals in tobacco control. Geneva: World Health Organization.

WHO Framework Convention on Tobacco Control (2018) 2018 GLOBAL PROGRESS REPORT on Implementation of the WHO Framework Convention on Tobacco Control.Geneva: World Health Organization.

World Health Organization (2019) WHO Report on the Global Tobacco Epidemic, 2019: Offer Help to Quit Tobacco use. Geneva: World Health Organization.

Yaddanapalli, S. et al. (2019) 'Awareness and Attitude toward Pictographs on Tobacco Products: A Population-based Study in Field Practice Area', Indian Journal of Psychiatry, 61(1), pp. 65-69. 